\title{
IoT Based Smart Energy Meter
}

\author{
Dr. Shreedhar A Joshi, Srijay Kolvekar, Y. Rahul Raj and Shashank Singh
}

\begin{abstract}
Smart meter is a next generation meter which is highly efficient and user friendly, which provides a great way to save and control the usage of energy. The smart meter is wirelessly connected to users by the means of IoT. This means user can easily have control on the meter as per his needs. The advantage of smart meter is it can be used by utilities to communicate information to bill customers and operating their electric system. Earlier the system utilized one way communication to collect meter data and were referred as AMR. But now due to sophisticated technology, AMI the system can communicate in two ways for both data collection, billing and to control the device.
\end{abstract}

Keywords--- Internet of Things (IoT), Automatic Meter Reading (AMR), Automatic Meter Infrastructure (AMI)

\section{INTRODUCTION}

$S_{\mathrm{d} e t}^{\mathrm{N}}$ MART energy meter has unit measuring meter. This device will be in turn connected to the main server with the help of IoT. The algorithm is such that, at the end of each month the device will generate the rate of units and send it to the user's smartphone along with the bill. The android application which will be connected to the same server where the smart meter is connected.

On the Smartphone user will get the bill on a monthly basis. The interesting feature is that the user can set his limit of consumption as per his requirement. The application will be having the option of online payments via credit cards or the specific id card. The meter will send both units and bills to the user. The user can also check the units on a daily basis.

The application will also have the option to optimize the bill based on his usage. And the user can also control the connected appliances with the help of Smartphone.

\section{DESIGN OF SYSTEM}

The system has mainly three modules. The first module will be the smart meter. The second module will be android application. And the third will be it server were first two modules will be connected. The first module will be a unit calculating meter. The meter will be interfaced with the Arduino board, this will be in turn connected to third

Dr. Shreedhar A. Joshi, Department of Electronics and Communication Engineering, SDM College of Engineering and Technology, Karnataka, India. E-mail:shreedhar.j@rediffmail.com

Srijay Kolvekar, Designation, Department of Electronics and Communication Engineering, SDM College of Engineering and Technology, Karnataka, India.E-mail:srijayjk@gmail.com

Y. Rahul Raj, Department of Electronics and Communication Engineering, SDM College of Engineering and Technology, Karnataka, India. E-mail:yrahulrajakshay@gmail.com

Shashank Singh, Department of Electronics and Communication Engineering, SDM College of Engineering and Technology, Karnataka, India. DOI:10.9756/BIJRCE.8209 module.i.e. Server. The server is created to handle HTTP request. The Android app will send HTTP request to the Arduino which will be connected to smart energy meter.

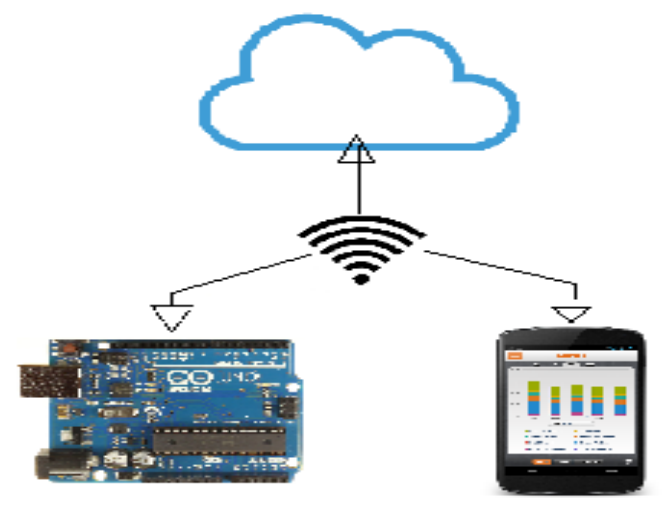

Figure 1: Design of System

\section{BLOCK DIAGRAM}

Fig. 2 gives the block diagram of the proposed architecture of the overall operation of the device. All the elements are illustrated in this block diagram. Here we use a simple LDR sensor to sense the rotations of meter, and this will be fed to Ardunio. It is known as Light Dependent Resistor which is a variable resistor, whose resistance goes high in the dark and goes low when it is exposed to light. This rotation will be converted into pulses by Ardunio, and the algorithm will calculate the units. This data will be saved on the server, which can be easily accessed by the user. The meter will also send an alert message when the consumption of units increases above the limit. The limit can also be set by the user as per his requirement.

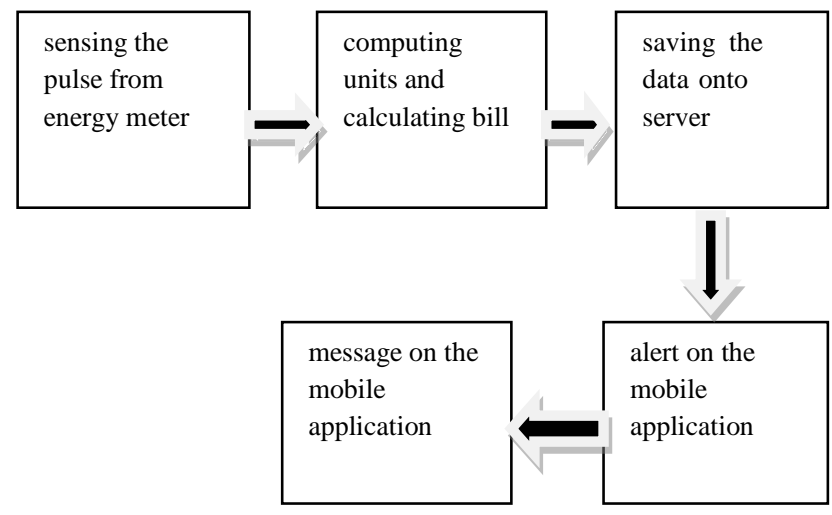

Figure 2: Block Diagram of System

\section{PRESENT SCENARIO OF ENERGy CONSUMPTION}

In public and municipal institutions and people consume energy without any utter consciousness. 
The practical reasons for consumption of energy is

\section{Illicit Consumption}

A large portion of the power generated used by the system is unpaid. That is, there is no proper collection of revenue on the generation, transmission and distribution of that power.

2. There is no targeted power generation and transmission. As results there will be many power cuts in rural and suburban areas.

3. Intangible demand:

The fact is that there are about $40 \%$ of the world's population, which are still to get electricity of which 400 million are Indian.

4. Most of the power will be drawn by unauthorized user by direct wire connection.

5. A large percentage of power is lost to inefficient distribution.

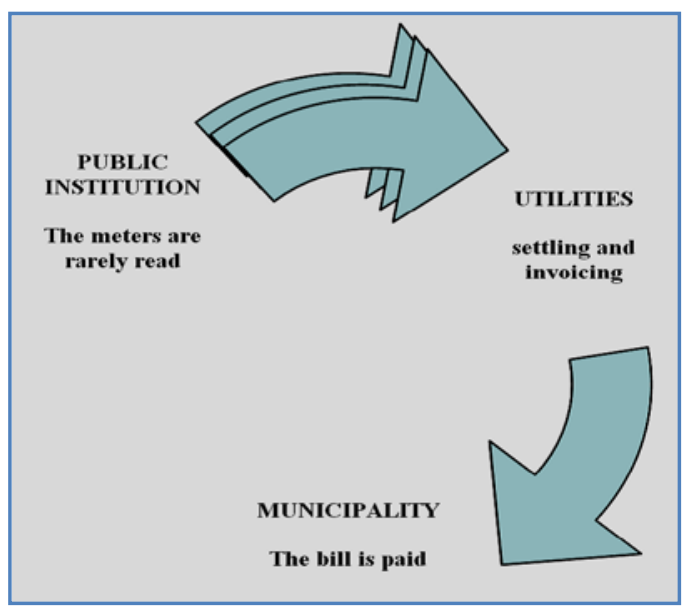

Figure 3

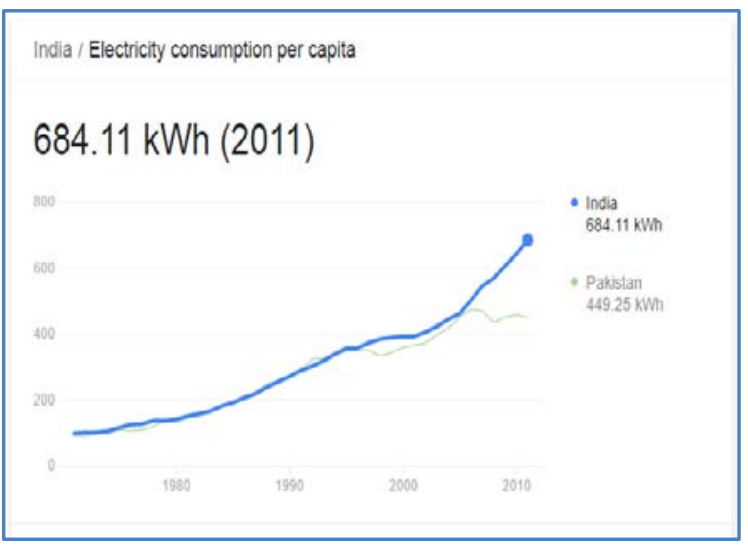

Figure 4: Consumption of Energy

\section{ENERGY CONSUMPTION AFTER IMPLEMENTATION}

1. The smart meter can record and measure the power consumption in small amount of time. By recording energy at these intervals, this allows the utility to bill customers using time of use pricing, Simply put the cost of energy meter through the day, therefore users will able pay bill at different price instead of flat rate.
2. Smart metering will have an AMI system where all the data are stored onto a web server . User can check his unit consumption at any time and can also pay the bill online.

3. The user will be able to set the limits for consumption. Beyond the limit of user will generate a warning message to the user.

4. Bill can be paid at any time online. There is no need for a person to come home and generate bills. All this work will be done by the system and it will be very reliable.

5. More accurate bills will be generated .

6. With the information on mobile, user can see immediately and adjust according to his need.

7. By making your energy usage more easily understood, you can make smarter decision to save energy and money, including feeling more comfortable switching energy supplier.

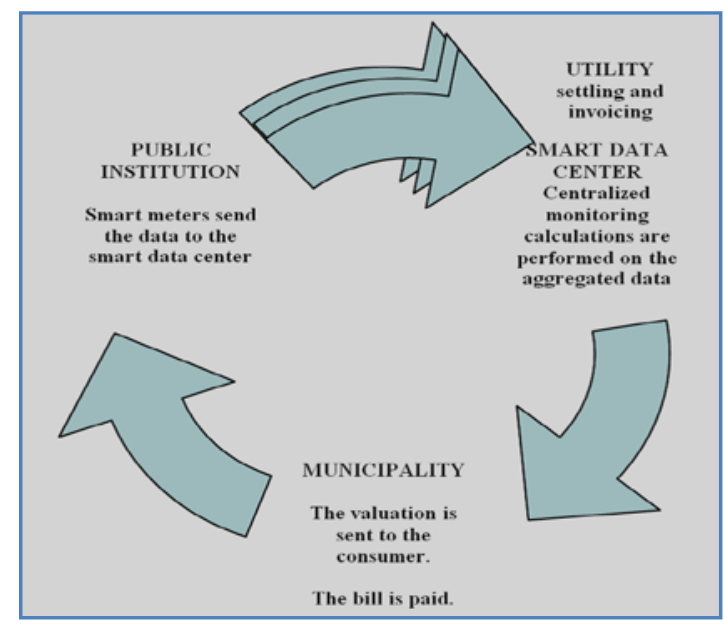

Figure 5: After Installiation

\section{BeNEFITS OF SMART ENERGy Meter}

1. There will be no more estimated bills. The user has to pay bills for what is actually used in a billing period.

2. The smart meter will report if it encounters any electrical issues to deliver better quality of supply.

3. It will facilitate pre payment facility.

4. Electricity providers can offer new schemes on usage of electricity.

5. It will be providing precise details of consumption. This will allow users to manage the usage of electricity.

6. The user can monitor the usage remotely.

7. The user can set his limits of consumption and crossing of this limit will generate warning message to the user.

\section{How MUCH IT WILL COST}

There is no extra charge for installation. Your smart meter will be installed by your energy supplier at no charge to you. The cost of the roll out is covered already in your energy bill the same way that installation and maintenance of traditional meters. 


\section{CONCLUSION}

The wide range of application makes smart energy meters to be used in all the private and public sectors. The usage of energy meter will reduce power consumption. This saving in power can be effectively used in other area, where there is scarcity of electricity.

\section{ACKNOWLEDGMENT}

The Author and co-authors would like to thank the Principal for providing for his continuous support in carrying out this project. The author would like to acknowledge the HOD, Department of Electronics and Communication Engineering, SDMCET for providing all the resources and ambience for carrying out the work.

\section{REFERENCES}

[1] The Race Is (Still) On: ZigBee vs. WiFi for Smart Energy Homes http://gigaom.com/cleantech/the-raceis-still-on zigbee vs-wifi-for-smartenergy-homes/

[2] Trilliantic Wite Papershttp://www.trilliantinc.com/library-files/ whitepapers/HAN_white-paper.pdf

[3] Wikipédia Wimaxhttp://hu.wikipedia.org/wiki/WiMAX

[4] On World: 100 Million New Smart Meters within the Next Five Years http://www.onworld.com/html/newssmartmeter.htm

\section{BIBLOGRAPHY}

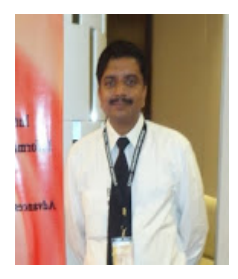

Dr. Shreedhar A Joshi from obtained a Doctoral degree Kuvempu University Shivamogga, Karnataka in wireless communication field. He has received B.E degree in Electronics and Communication from Karnataka University Dharwad in 1994 and M. Tech degree in Digital Electronics from VTU Belgaum in 2001. Presently he is working as a Professor in Department of Electronics and communication, SDM College of Engineering Dharwad India. He has published many papers in international journals and conferences.

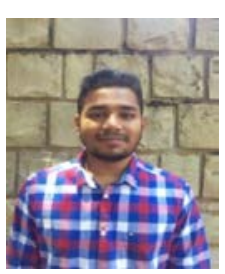

Srijay Kolvekar Persuing engineering from SDM College of Engineering and Technology, Dharwad.

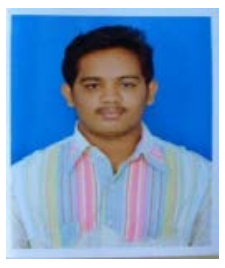

Shashank Singh BS Persuing engineering from SDM College of Engineering and Technology,Dharwad.

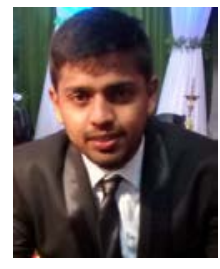

Y. Rahul Raj Persuing engineering from SDM College of Engineering and Technology,Dharwad. 